\title{
How structural multi-platform newsroom features and innovative values alter journalistic cross-channel and cross-sectional working procedures
}

\author{
Lischka, Juliane A
}

\begin{abstract}
This study explores the influence of multi-platform structural newsroom features and individual innovative values on journalistic cross-channel and cross-sectional working procedures. According to results of an online survey of print and online business journalists associated with multi-platform news outlets in the Germanspeaking area of Switzerland: (1) multi-platform reporting is strongly connected to innovative values of journalists, which in turn (2) changes cross-channel-(3) but not cross-sectional-working procedures. A multi-platform strategy is effective in overcoming procedural inertia, which is essential to maximizing innovative capacities of a news organization.
\end{abstract}

DOI: https://doi.org/10.1080/16522354.2015.1027114

Posted at the Zurich Open Repository and Archive, University of Zurich

ZORA URL: https://doi.org/10.5167/uzh-112836

Journal Article

Originally published at:

Lischka, Juliane A (2015). How structural multi-platform newsroom features and innovative values alter journalistic cross-channel and cross-sectional working procedures. Journal of Media Business Studies, 12(1):7-28.

DOI: https://doi.org/10.1080/16522354.2015.1027114 


\title{
How structural multi-platform newsroom features and innovative values alter journalistic cross-channel and cross- sectional working procedures
}

\author{
Juliane A. Lischka
}

University of Zurich

IPMZ - Institute of Mass Communication and Media Research

Andreasstrasse 15

CH-8050 Zurich, Switzerland

Tel. +41 (0)44 6352075

Fax +41 (0)446344934

E-Mail: j.lischka@ipmz.uzh.ch

Published as:

Juliane A. Lischka (2015) How structural multi-platform newsroom features and innovative values alter journalistic cross-channel and cross-sectional working procedures, Journal of Media Business Studies, 12:1, 7-28, DOI: 10.1080/16522354.2015.1027114

ACKNOWLEDGEMENTS The author wishes to thank Anika Bundi, Funda Güngör, Jannine Kamm, and Finn Sulzer for conducting the fieldwork for this study. The author is grateful to Bartosz Wilczek as well as an anonymous reviewer for their valuable comments on the paper.

ABSTRACT This study explores the influence of multi-platform structural newsroom features and individual innovative values on journalistic cross-channel and cross-sectional working procedures. According to results of an online survey of print and online business journalists associated with multiplatform news outlets in the German-speaking area of Switzerland: (1) multi-platform reporting is strongly connected to innovative values of journalists, which in turn (2) changes cross-channel(3) but not cross-sectional-working routines. A multi-platform strategy is effective in overcoming procedural inertia, which is essential to maximizing the innovative capacities of a news organization.

KEYWORDS Inertia; innovation; media convergence; business journalism; newspaper; newsroom convergence 
How structural multi-platform newsroom features and innovative values alter journalistic cross-channel and cross-sectional working procedures

FINAL PROOF

\section{INTRODUCTION}

After decades of successfully supplying news to the reader's and advertiser's markets, journalism recently underwent a disruptive period. Specifically, during the past 10 years, technological innovations and communication devices shifted young audiences, in particular, toward online sources. In addition, a financial crisis led to decreased advertising income for print media that online advertising income cannot balance out.

Media companies have reorganized themselves in order to create and produce output for multiple platforms and to adapt their processes for producing content that meets online requirements. A primary challenge is to reach and attract audiences by presenting news on various channels in a reader-friendly way: "media professionals have to learn to take into account the changing demands of audiences, the consequences for their news companies and the effects on their work" (García Avilés, Meier, Kaltenbrunner, Carvajal, \& Kraus, 2009, p. 301). In addition, Deuze (2008b, p. 860) states that journalism has not found answers to these environmental developments and criticizes that journalism "does not seem to be able to engage the consumer-citizen in a meaningful way." Achtenhagen and Raviola (2009) report about interdependent structural, procedural, and cultural tensions in the process of reorganization, which may cause rigidity and, in turn, dysfunction in news organizations if not actively managed.

This study's goals are: (1) to provide a theoretical model to explain structural, value-based, and procedural change and inertia in newsrooms, and (2) to understand their interconnections and the potential of a multi-platform strategy in the context of value-based and procedural change in newsrooms. The overall research question is whether structural multi-platform features and individual characteristics can overcome journalistic routine rigidity, which is an important precondition for innovation.

Empirically, this study uses business journalists in the German-speaking area of Switzerland (covering two thirds of the total Swiss population) as a research example. Journalists of other beats than business were not included to avoid variations resulting from the different topics journalists 
How structural multi-platform newsroom features and innovative values alter journalistic cross-channel and cross-sectional working procedures

FINAL PROOF

cover. The economy is a "permanently salient issue of the public discourse" (Hagen, 2008, p. 527) and economic coverage has increased dramatically in recent years as a result of the global financial crisis (see e.g. Lischka \& Siegert, 2013 for business news development between 2002 and 2011 in Germany and Switzerland).

In Switzerland, by the end of 2010, online and print editorial offices were established. In 2010, nearly three quarters (73\%) of Swiss internet users read news online - a share that has almost doubled since 2004 and is fairly similar across age groups (Bundesamt für Statistik, 2012, pp. 25, 72). In addition, newspaper revenues have stagnated in Switzerland, which led to a reduction in editorial staffing, editorial reorganization, and increased synergy exploitation within and outside news organizations (Meier \& Leonarz, 2011; Zwicky, 2012). Therefore, convergence efforts of former print-only news outlets should reveal effects on journalistic values and working routines.

\section{LITERATURE REVIEW}

\section{Organizational change and inertia}

In organizational research, the environment is a direct setting of the company and envelops "change in customer tastes, production or service technologies, and the modes of competitions" (Miller \& Friesen, 1983, p. 233). Economic conditions or technological change causes uncertainty and pressures the organization to change as its practice becomes dysfunctional (Burke, Lake, \& Paine, 2009, p. 2). Hence, "a turbulent environment triggers adaptive behaviour in organisations" (Blackmore \& Nesbitt, 2009, p. 146). One response to uncertainty is described as an engagement in tight coupling with the environment according to rational-choice theory (Pfeffer \& Salancik, 2003) (i.e., monitoring and assessing customers and resources or sharing information across divisions within an organization)

However, firms do not constantly adapt to their environment, as the "power of inertia" (Corstjens, Umblijs, \& Wang, 2011) is often more compelling. Structural inertia occurs when the 
How structural multi-platform newsroom features and innovative values alter journalistic cross-channel and cross-sectional working procedures

FINAL PROOF

speed of the reorganization is much slower than the change in environmental conditions (Hannan \& Freeman, 1984). In a turbulent situation, it may be rational for decision makers, who wish to secure their career, not to apply disruptive (i.e., untested) technologies (Christensen, 1997). This is one explanation for inertia resulting in organizational stagnation. Another result is isomorphism because "organizations seek legitimacy by becoming more like others in their environments" (Lowrey, 2005, p. 497). According to institutionalism, organizations engage in loose coupling when facing environmental uncertainty. In other words, these organizations maintain established practices that have resulted in institutional legitimacy (Zucker, 1987) because they "compete not just for resources and customers, but for political power and institutional legitimacy, for social as well as economic fitness" (Powell \& DiMaggio, 1991, p. 66). Hence, in the face of disruptive environmental change, a rapid adaption of organizations may be unlikely.

Indeed, although editors scrutinize their online audience by monitoring online audience metric data and discussion forums, this enquiry may not lead to changes in professional practice (Lowrey \& Woo, 2010, p. 53). Although audience behavior is discussed in news meetings, news decisions are not altered in response to audience behavior. Lowrey and Woo (2010) argue that news organizations pursue conventional practices "in order to demonstrate legitimacy and to avoid claims of negligence" (Lowrey \& Woo, 2010, p. 44). At most, news organizations mimic and reproduce dominant practices of other organizations in their field (Deuze, 2008; Lowrey, 2005).

\section{Multi-platform implementation and inertia in news organizations}

Although news organizations have increasingly moved from a mono- to a multi-platform outlet, the editorial practice "seems to straddle the re-enactment of established forms" (Mitchelstein \& Boczkowski, 2009, p. 562) and the level of actual innovation remains low within news organizations - or at least lower than expected (Lowrey, 2011; Steensen, 2009). An early notion on convergence efforts made by a journalist cited by Lowrey (2005, p. 495) reveals an "allure of 
How structural multi-platform newsroom features and innovative values alter journalistic cross-channel and cross-sectional working procedures FINAL PROOF

'keeping up appearances"” (Lowrey, 2005, p. 496), "Everybody thinks everybody else is doing it. The few who are actually doing it aren't very good at it."

Gilbert $(2005$; 2006) offers an explanation for this paradox of structural organizational change and routine rigidity, outlining the process of newsroom convergence from an organizational perspective. First, a new external context requires competency configuration (towards online competencies) but meets a certain historical context and traditional (print) competencies of the news organization (Gilbert, 2006, p. 150). Gilbert (2006, p. 151) argues that traditional competencies may fit with the internal situation: "This internal coherence makes it difficult to change part of the capability set without pulling the system apart entirely." One consequence is that incumbent firms invest "in their current market position and not in the new technology" (Gilbert, 2005, p. 742). Resource rigidity (Gilbert, 2005) likely takes place after long periods of success (Miller, 1994), which was the case for news organizations until the turn of the century.

At the same time, the traditional print competency may retain a "residual fit between internal capabilities and a portion of the external environment" (Gilbert, 2006, p. 151). Due to this residual fit, there is no initial performance decline, and therefore the environmental change may not be initially perceived as a great opportunity, which in turn makes it difficult for established firms to motivate a response. Domingo (2008, p. 681) reveals that the professional culture of traditional journalism turns interactivity "into a problem to deal with instead of an opportunity for change." Consequently, the need for competency configuration while traditional competencies retain a residual fit resulted that many news organizations turned from a mono- to a multi-platform news outlet. The new area of competence structurally differentiated from the parent organization by establishing an online unit in addition to a print unit during the first decade of the 2000s. This separation enabled different behaviors to be enacted instantaneously across both subunits of the news organization. As a long-term result, newspapers maintain traditional textual features, whereas broadcasters frequently use traditional visual features (Himelboim \& McCreery, 2012). In addition, journalists traditionally use blogs to enhance "traditional journalistic norms and practices" and remain gatekeepers while blogging 
How structural multi-platform newsroom features and innovative values alter journalistic cross-channel and cross-sectional working procedures FINAL PROOF

(Singer, 2005, p. 173). Likewise, Swiss news outlets use their Twitter page as an additional channel for the distribution of articles instead to engage with the audience (Eisenegger, Orizet, \& Schranz, 2013)

Only after print and online competencies coexist for a certain amount of time can a process of convergence begin (Gilbert, 2006). In the late 2000s, central desks that feed material to multiple platforms were installed (Phillips, Singer, Vlad, \& Becker, 2009, p. 69). For convergence, routine rigidity, which refers to "failure to change organizational processes" (Gilbert, 2005, p. 741), must be overcome.

\section{Multi-platform strategy and routine rigidity}

Although the converged newsroom structure plays an important role in the innovations process (Meier, 2007), news organizations are slow to adapt their practices to the internet era and are more innovative in ways that are consistent with past habits than adopting new ones (Himelboim \& McCreery, 2012; Ryfe, 2009). Meier (2007, p. 6) states that the challenge for Central European news outlets "lies not only in repurposing content across platforms, but also in cross-departmental thinking and acting."

Rigid working procedures are found in various examples of journalism literature. Singer (2004) reveals that journalists in four U.S. newsrooms consider converged newsrooms to be advantageous and a successful editorial strategy for the whole news industry; however, cooperation among people working in a converged newsroom is comparably low. The diffusion of convergence may be delayed by different newsroom cultures that evolved during separate print and online subunits existed. Ryfe (2009) maintains that the daily routine of newsgathering combined with the inability or unwillingness of journalists to alter this routine - in which reporters significantly invested —is responsible for a lack of reporting changes. He argues that journalists may have collectively imagined that a change in reporting would be very costly and involve many resources for themselves personally. Therefore, only when journalists did not previously invest much in a certain routine, which may be the case with 
How structural multi-platform newsroom features and innovative values alter journalistic cross-channel and cross-sectional working procedures FINAL PROOF

younger and less experienced journalists (Ryfe, 2009, p. 679), have traditional routines been followed less rigidly. In this manner, newspapers with younger web staff also offer more interactive features on their websites (Larsson, 2012).

Similar to Achtenhagen and Raviola (2009), who report about interdependent structural, procedural, and cultural tensions in the process of newsroom reorganization, Steensen (2009) argues that five highly integrated factors determine the process of innovation in online newsrooms: (1) newsroom autonomy, (2) newsroom work culture including audience perception, (3) the role of management, (4) the relevance of new technology, and (5) innovative individuals. Further, Steensen argues that the role of the individual in the innovation process has been undervalued in previous research. Individuals within newsrooms have to regard innovation as part of the practice of journalism. For the role of innovative individuals, Massey and Ewart (2012, p. 207) conclude that "[a]greeing with the goals for change, feeling involved in change, and believing that managers managed change well" lead to support for change and overcoming rigidity.

Thus, the innovation process is determined not only by structures, but also by individuals and interactions (Slappendel, 1996). The structural perspective assumes that innovation develops based on the goal of the organization to survive in the face of environmental change, whereas the individualist perspective presumes that individuals, equipped with personal innovative qualities, or groups of élites, that share innovative beliefs and values, are the major source of change in organizations (Slappendel, 1996, pp. 110, 111, 114). The interactive process perspective regards the interconnection between action and structure as crucial to the innovations process (Slappendel, 1996, p. 119).

\section{Theoretical conclusion and research questions}

Rational-choice theory and institutionalism propose that, in the case of environmental uncertainty, organizations adjust and stagnate or assimilate, respectively. Rational choice theory expects that organizations employ tight coupling with their environment, which leads to organizational change and innovation. Individual and structural aspects in an organization can lead to overcoming inertia and 
How structural multi-platform newsroom features and innovative values alter journalistic cross-channel and cross-sectional working procedures

FINAL PROOF

reinforce innovation (Slappendel, 1996; Steensen, 2009). On the other hand, institutionalism expects that organizations apply loose coupling with their environment, tend to continue with established resource investments and routines, and mimic the changes of other organizations (Gilbert, 2005; Lowrey \& Woo, 2010). These theoretical perspectives are summarized in Figure 1.

Figure 1: Theoretical perspectives on organizational responses to environmental uncertainty

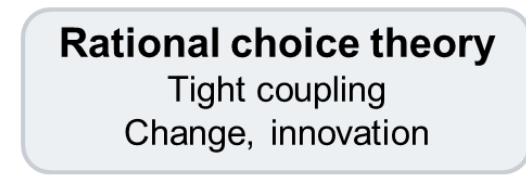

News organizations are businesses that strive to remain functional and therefore adapt in the face of environmental uncertainty.

$\begin{array}{cc}\begin{array}{c}\text { Structuralist } \\ \text { perspective }\end{array} & \begin{array}{c}\text { Individual } \\ \text { perspective }\end{array} \\ \text { Multi-platform } & \text { Journalistic values } \\ \text { strategies evolve, } & \text { and beliefs } \\ \text { news channels } & \text { change, innovative } \\ \text { converge. } & \text { potential } \\ \text { increases. }\end{array}$

Source: Compiled by the author.

\section{Institutionalism}

Loose coupling Inertia

News organizations are social and cultural institutions that maintain established practices ensuring institutional legitimacy.

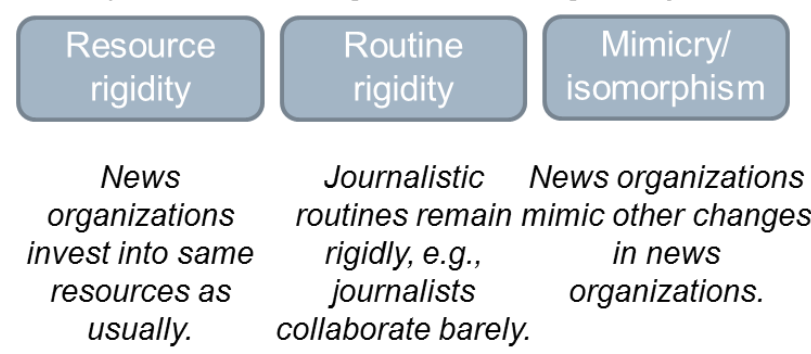

This study investigates whether innovative values of journalists as well as structural differences in newsrooms that result from a multi-platform strategy (i.e., serving online and print channels, having centralized newsrooms and open-plan offices) are sufficient to overcome routine rigidity. Following Meier's (2007) claim for convergent and cross-departmental thinking and acting, this study regards, in line with Deuze (2004a, p. 140), the level of "cooperation and collaboration between formerly distinct media newsrooms" and sections as converging cross-channel and cross-beat routines.

Hence, this study links the individual and structuralist perspectives to routine rigidity and investigates the following research questions and hypotheses:

RQ1. To what extent are journalists' innovative values related to structural aspects of a multiplatform strategy? 
How structural multi-platform newsroom features and innovative values alter journalistic cross-channel and cross-sectional working

H1: Serving multiple channels, working in an open-plan office, and the existence of a central news desk are related to increased innovative values.

RQ2. Do structural multi-platform features and journalists' innovative values lead to less rigid working procedures?

H2: Journalists who rate innovative values as important and work in a multi-platform environment frequently work in a converged state across channels.

H3: Journalists who rate innovative values as important and work in a multi-platform environment frequently collaborate across beats.

\section{METHOD}

\section{Measurement}

Data collection was conducted using a structured online questionnaire, collecting information on the multi-platform strategy of the news outlet, the newsroom structure within the news outlet, the journalist's cross-channel convergence working level, level of cross-beat collaboration, innovative abilities, and sociodemographics (i.e., gender, age, level of education, years of professional experience, and accountability in management) of business journalists. The questionnaire language was German.

Questions on the structural features (i.e., the newsroom structure and the working environment) asked whether the journalist most frequently works in an open-plan office or in a single office, whether the editorial office possesses a central news desk, and whether the journalists work for print and/or online channels. The former two features relate to the internal architectural working environment, and the latter relates to working procedures.

For the level of cross-channel convergence, the measures are based on the stages of the convergence continuum of Dailey, Demo, and Spillman (2005) (see Figure 2) that describe 
How structural multi-platform newsroom features and innovative values alter journalistic cross-channel and cross-sectional working procedures

FINAL PROOF

convergence partnerships as they are adapted to the convergence of platforms within the same organization.

Figure 2: Convergence continuum

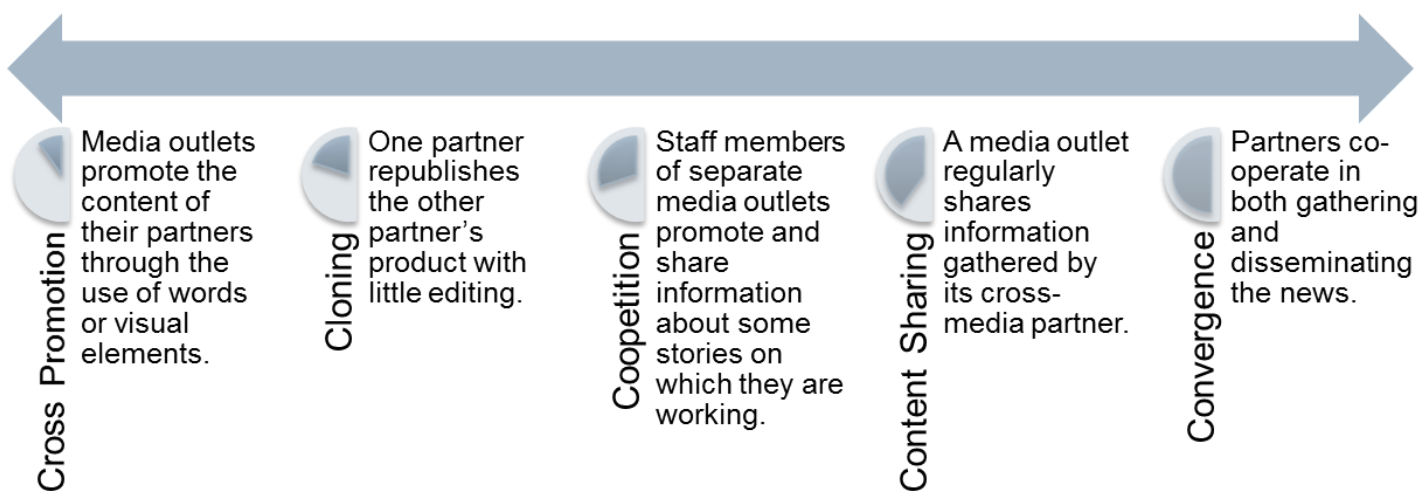

Source: Adapted from Dailey et al. (2005, pp. 153-154).

Adapted to intra-company convergence, these stages reveal whether cross-channel cooperation exists in a news company. The examples used for measuring include the forms of content distribution and cross-media practice as suggested by Erdal (2011). Following are the measured levels of convergence:

1. Cross promotion:

a) I use text or visual elements to promote the cooperation between both media channels (i.e., I call the attention of readers to additional information on our website, or vice versa). b) I refer in a print article to additional information online, or vice versa.

2. Cloning: I publish a report with slight adjustments on another media channel (e.g., an article for the newspaper is also published online, or vice versa).

3. Coopetition: I investigate separate information on a topic but share this information with editors of the other channel.

4. Content Sharing: I regularly meet with journalists of the other channel to exchange information and ideas and we jointly develop projects.

5. Convergence: 
How structural multi-platform newsroom features and innovative values alter journalistic cross-channel and cross-sectional working procedures FINAL PROOF

a) I share my work space with journalists of the other channel and we jointly develop new ideas and use the strengths of both media channels to best tell the story.

b) Our editorial office does not differentiate between print and online channels. I work similarly for both channels.

Hence, the convergence levels 1 and 2 relate to the presentation of journalistic output, whereas convergence levels 3,4 , and 5a relate to working processes. Convergence level $5 \mathrm{~b}$ relates to the general position of multi-channels within the editorial office. The frequency of working convergence is measured on a 6 -point Likert scale from $0=$ never to $5=$ always. The convergence questions were only asked when the news outlet employed a multi-platform strategy.

The frequency of cross-beat collaboration is measured with the question "How often do you collaborate with journalists of other beats or topics?" on a 6-point Likert scale from $0=$ never to $5=$ always. For analysis, the convergence and collaboration scales are converted to $1=$ never to $6=$ always.

The measurement of innovative values is based on the critiques of García Avilés et al. (2009) and Deuze (2008b), in which new developments and audience demands are not sufficiently considered by journalists and refer to the convergence mindset of journalists mentioned by (Kolodzy, 2006) as well as partly to Sylvie's and Moon's (2007, p. 91) description of journalistic change-agents as "open, responsive, innovative, trustworthy, and sincere." The following measured characteristics identify whether journalists can overcome routine rigidity and the innovative ability in addressing the audience:

- A journalist is open to new technologies.

- A journalist is open to new working procedures.

- A journalist develops new ideas for addressing the audience.

- A journalist identifies new trends in reporting. 
How structural multi-platform newsroom features and innovative values alter journalistic cross-channel and cross-sectional working procedures FINAL PROOF

The level of importance is measured on a 6-point Likert scale from $0=$ of absolutely no importance to $5=$ very important. For analysis, the scale is converted to $1=$ of absolutely no importance to $6=$ very important.

\section{The case of Switzerland}

As previously mentioned, the challenge for Central European news outlets "lies not only in repurposing content across platforms, but also in cross-departmental thinking and acting" (Meier, 2007, p. 6). In German-speaking newspapers, traditionally, each journalist formerly worked decentralized for a certain beat or department working in single offices lacking a clear and hierarchical role differentiation into reporter, news editor, subeditor, production editor, etc. (Esser, 1998; Wilke, 2003). Such decentralized news departments are more difficult to manage compared to a top-down linear hierarchy such as found in British or American newspapers (Esser, 1998, p. 395).

Centralized newsrooms, open-plan offices, and multiple-platform publishing is relatively new to German and Swiss news organizations. Many news organizations traditionally employed a separate editorial office for their online channel. In Switzerland, by the end of 2010, online and offline editorial offices were often separate, however, they exchanged content. Some news outlets had a central news desk for online and print editorial offices, but few were fully integrated (e.g., the tabloid newspaper Blick, published by Ringier AG, or the publisher AZ-Medien (Keel, Wyss, Stoffel, \& Saner, 2010, p. 5). In 2012, formerly separate online and print newsrooms converged at the Neue Zürcher Zeitung, a supra-regional daily quality newspaper published by NZZ-Mediengruppe (Wilczek, 2014).

Quality differences between online and print content prove a low level of online and print convergence in Switzerland (Schranz \& Eisenegger, 2012). Online sites publish less news than their print counterparts. Online news are more strongly based on agency reports or are more frequently paraphrased from other news media. A high publishing frequency and a click rate-based online journalism as well as low advertising income and scarce resources are responsible for lower quality content online (Keel et al., 2010; Schranz \& Eisenegger, 2012). 
How structural multi-platform newsroom features and innovative values alter journalistic cross-channel and cross-sectional working procedures FINAL PROOF

\section{Fieldwork and sampling}

We conducted an online survey of Swiss business journalists of former print-only general and business news outlets in the German-speaking area of Switzerland in spring/summer 2014 covering the major Swiss news organizations

The online questionnaire was programmed and the fieldwork conducted by a team of students. In total, 130 email addresses of distinct business journalists of print and online news outlets (i.e., two daily supra-regional quality newspapers, six regional newspapers, two Sunday newspapers, two supra-regional tabloids, one weekly business newspaper, two business magazines, and their online counterparts) were researched via homepages of the news outlets, articles within the business sections, and the imprint. The association of business journalists of Zurich (Club der Zürcher Wirtschaftsjournalisten), which is the only association of business journalists in Switzerland and is open to all business journalists working in Switzerland, consists of approximately 120 members. Therefore, the number of collected email addresses should constitute the population of actively working business journalists in print and online news outlets. Obtaining the members' email addresses was not possible.

Personal email invitations and follow-up reminders were sent out between April and July 2014. The long fieldwork period is due to the stepwise search for email addresses. For 12 business journalists, the email addresses remained incorrect after additional desk research. Hence, the adapted population and the number of invited journalists diminishes to 118 (100\%). Of those invited, $60(51 \%)$ opened the online survey and a satisfying number of 47 (40\%) business journalists completed the questionnaire. The majority of dropouts occurred on the welcome page and the first page of the questionnaire. On average, the respondents needed seven minutes to complete the questionnaire. Due to the high return rate of NZZ-Mediengruppe, business journalists of this publisher are overrepresented in the sample compared to the adjusted population (see details in Table 1). 
How structural multi-platform newsroom features and innovative values alter journalistic cross-channel and cross-sectional working procedures FINAL PROOF

Table 1: Population, sample, and return rate of business journalists per publisher

\begin{tabular}{|c|c|c|c|c|c|c|c|c|}
\hline & & $\begin{array}{c}\text { NZZ- } \\
\text { Medien- } \\
\text { gruppe }\end{array}$ & Tamedia $A G$ & Ringier $A G$ & AZ Medien & $\begin{array}{c}\text { Axel } \\
\text { Springer } \\
\text { Schweiz } A G\end{array}$ & Other & Total \\
\hline \multirow{2}{*}{$\begin{array}{l}\text { Discovered } \\
\text { population } \\
\text { No valid } \\
\text { email address }\end{array}$} & $\mathrm{n}$ & 18 & 39 & 11 & 20 & 31 & 11 & 130 \\
\hline & $\mathrm{n}$ & 0 & 2 & 3 & 3 & 2 & 2 & 12 \\
\hline \multirow{2}{*}{$\begin{array}{l}\text { Adjusted } \\
\text { population }\end{array}$} & $\mathrm{n}$ & 18 & 37 & 8 & 17 & 29 & 9 & 118 \\
\hline & $\%$ & $15 \%$ & $31 \%$ & $7 \%$ & $14 \%$ & $25 \%$ & $8 \%$ & $100 \%$ \\
\hline \multirow{2}{*}{$\begin{array}{l}\text { Respondent } \\
\text { sample }\end{array}$} & $\mathrm{n}$ & 14 & 14 & 3 & 5 & 9 & 2 & 47 \\
\hline & $\%$ & $30 \%$ & $30 \%$ & $6 \%$ & $11 \%$ & $19 \%$ & $4 \%$ & $100 \%$ \\
\hline Return rate & $\%$ & $78 \%$ & $38 \%$ & $38 \%$ & $29 \%$ & $31 \%$ & $22 \%$ & $40 \%$ \\
\hline
\end{tabular}

One remark of a journalist to the questionnaire should be noted, stating that newsroom convergence is primarily a PR exercise rather than a reality in her/his editorial office, which is another form of the "allure of "keeping up appearances"” (Lowrey, 2005, p. 496). Yet the questionnaire asked for an evaluation of individually experienced frequencies and individual evaluations for each journalist. Therefore, the answers were expected to be individually valid.

\section{Sample description}

All surveyed journalists work for a former print-only news outlet with a multi-platform strategy comprised of both print and online channels (i.e., the homepage, Facebook, and Twitter pages of the news organization). Journalists report that Google news or Google+ are very rarely used. Further online channels were not mentioned.

According to Table 2, 23 (49\%) of the responding business journalists work in print and online channels, 22 (47\%) work in print only, and two in online only. Alternatively, 24 (51\%) journalists work in an editorial office containing a central news desk, 34 (72\%) work mostly in an open-plan office, 13 (28\%) mostly in an individual office, and 9 (19\%) of the journalists (almost) always work together with journalists of other beats or topics in their editorial office. Roughly one quarter of the business journalists are female (23\%). On average, the business journalists are 41 years old, have 13 
How structural multi-platform newsroom features and innovative values alter journalistic cross-channel and cross-sectional working procedures

FINAL PROOF

years professional experience and have been working for the current news outlet for five years. Three out of ten surveyed business journalists have (almost) always managerial responsibility (30\%).

There is only one significant difference in the working environment between journalists working mono- and multi-channel: multi-channel journalists work more often in an outlet that has a central news desk in the editorial office ( $74 \%$ vs. $29 \%$, significant difference, $Z$-test, $p<.05$ ).

Table 2: Working environment and demographics of the sample

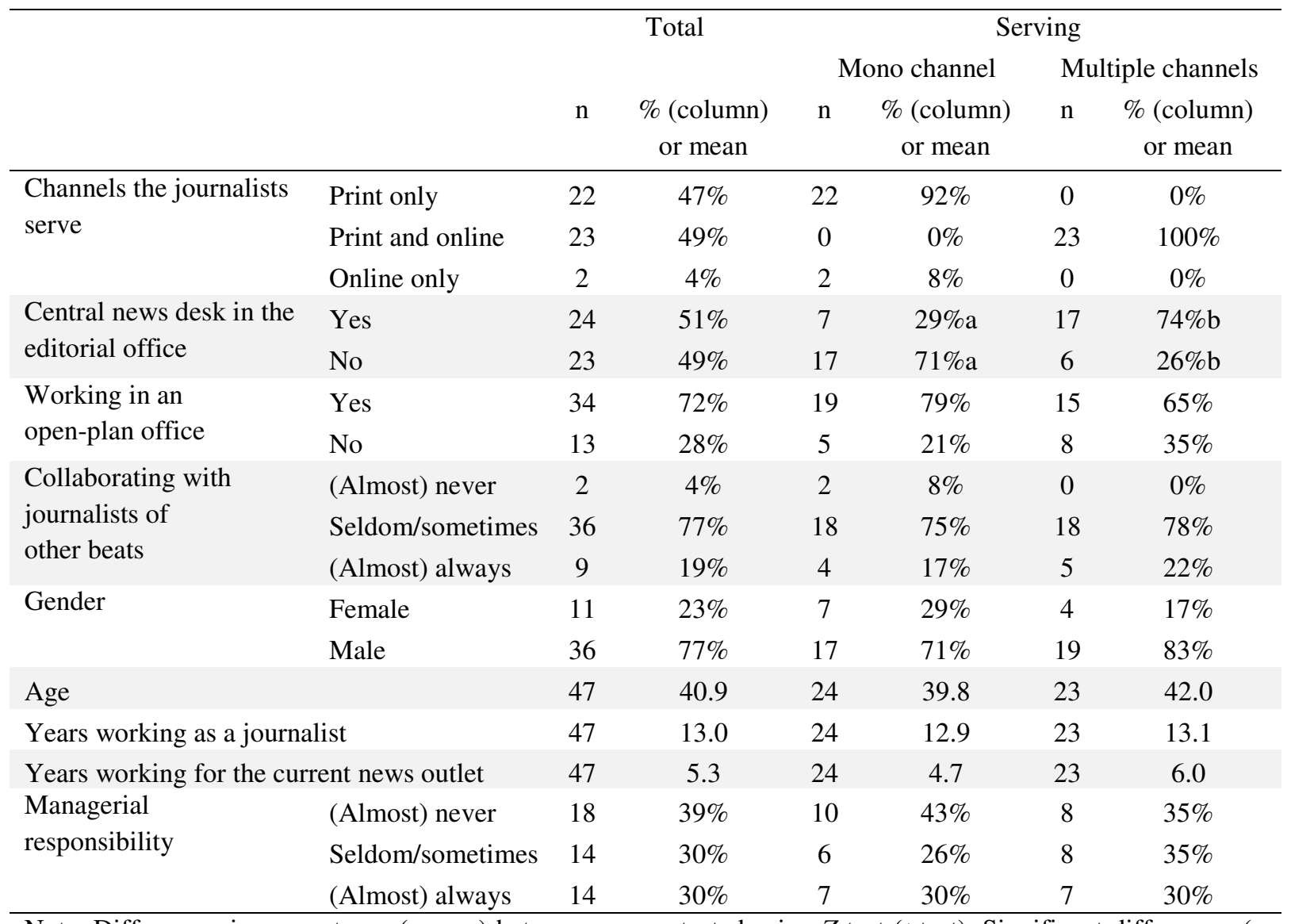

Note. Differences in percentages (means) between groups tested using Z-test ( $t$-test). Significant differences $(p$

$<.05)$ indicated with subscripts ${ }_{a}$ and $_{b}$. 
How structural multi-platform newsroom features and innovative values alter journalistic cross-channel and cross-sectional working procedures

FINAL PROOF

\section{RESULTS}

\section{To what extent are journalists' innovative values related to structural aspects of a multi-platform} strategy?

The first research question relates to the connection between individual and structuralist perspectives in Figure 1. The individual perspective is measured with a set of four innovative values (Cronbach's alpha $=.836$, which decreases when any of the four items is deleted) and a mean index based on the four items. An open question followed the item measuring new ideas for addressing the audience, where the journalists were asked to give examples for news ways of addressing the audience. The responses related to the following two dimensions: (1) the news channel (e.g., social media in general, Twitter, or LinkedIn or (2) the mode of audience addressing (e.g., short sentences, info graphics, meeting readers in their everyday situation, and using data journalism platforms). Structuralist features comprise whether journalists work for multiple channels (print and online) versus one channel (print or online), working in an open-plan versus single office, and whether a central news desk exists.

Mean comparisons reveal differences in innovative values among groups of journalists in different newsroom structures (Table 3). When working multi-channel (i.e., for print and online channels), journalists rate all innovative values as significantly more important than journalists working for only one channel. When working in an open-plan office, journalists rate their openness to new working procedures as significantly more important than journalists working in single offices. The existence of a central news desk is related to an increased importance evaluation of being open to new working procedures, developing new ideas for audience addressing, and detecting new trends in reporting — but not to an increased openness to new technologies.

For H1, results reveal that only multi-channel working is related to an increase in innovative values whereas interior architectural features, such as the office structure, is not related. Therefore, H1 can be partly accepted. 
How structural multi-platform newsroom features and innovative values alter journalistic cross-channel and cross-sectional working procedures

FINAL PROOF

\section{Do structural multi-platform features and journalists' innovative values lead to less rigid working} procedures?

$\mathrm{H} 2$ and $\mathrm{H} 3$ assume a relation between innovative values and structural newsroom features with cross-channel and cross-beat collaboration. Cross-channel collaboration is measured with the convergence model adapted from Dailey et al. (2005) (Cronbach's alpha $=.845)$. As described previously, for analysis, the convergence levels are separated into output- and process-related convergence (Cronbach's alpha $=.787$ and .826 , respectively). Output-related convergence (i.e., using stories for print and online channels) occurs "seldom" to "sometimes" on average (Table 5). Processrelated convergence (i.e., exchange between print and online journalists) occurs "seldom" on average. Collaboration across beats occurs "sometimes" on average.

First, correlations between cross-channel and cross-beat collaboration with innovative values (Table 4) reveal that the first six convergence steps positively relate to the innovative value index. Whether journalists work similarly for print and online channels (convergence b), is only positively related to the importance of detecting new trends in audience addressing. All convergence levels are most strongly positively related to the importance of detecting new trends in audience addressing and identifying new trends in reporting. For openness to new technologies and working procedures, relations rarely exist. Collaboration across beats is not related to innovative values.

Second, differences in collaboration frequency across print and online channels by means of the convergence levels and collaboration across beats are compared using structural newsroom features (Table 5). Results reveal that multi-channel journalists more frequently cross promote content online in the print channel, clone content between print and online channels, share information across channels (coopetition and content sharing), and work similarly for both channels. However, multichannel journalists do not develop new ideas together with colleagues of other channels more often than journalists working for one channel (convergence a). When a central news desk exists in the editorial office, journalists more often cross promote online and print content, more frequently 
How structural multi-platform newsroom features and innovative values alter journalistic cross-channel and cross-sectional working procedures

FINAL PROOF

develop new ideas with journalists of other channels, and often work similarly for both channels. Working in a single or open-plan office does not lead to changes in cross-channel or cross-beat collaboration

In addition, OLS regressions of the two innovative values regarding audience addressing and reporting trends, the structural newsroom features, existence of a central news desk and multi-channel working, as well as demographic control variables on a mean index of the output-related (cross promotion and cloning), as well as the process-related convergence levels (coopetition, content sharing, and convergence a) is performed (Table 6). Results of the output-related convergence index reveal that a 1-point increase in the innovative value audience addressing leads to a .348 increase in the output-related convergence frequency. The existence of a central news desk leads to a .843 increase in the output-related convergence frequency, which is almost one point of the scale. Working multi-channel tends to lead to an increase of .648 in the output-related convergence frequency. Regarding the Beta coefficients, the strongest impact is on the existence of a central news desk and the innovative value in audience addressing. Demographic variables reveal no significant impact. Results on the process-related convergence frequency partly differ. Innovative values have no significant impact. The existence of a central news desk tends to increase process-related convergent collaboration by almost one point of the scale. Also, when journalists have managerial responsibility, process-related convergence increases. However, no demographical effects, such as age of professional experience, can be found. For cross-beat collaboration, no significant regressors are detected.

For H2, it can be concluded that journalists who rate identifying new ideas for audience addressing and new trends in reporting as more important, commonly prepare output for print and online channels (output-related convergence) but do not necessarily collaborate more often with colleagues of other channels (process-related convergence). Journalists whose office has a central news desk work commonly work in a converged setting. Therefore, we partly accept H2. 
How structural multi-platform newsroom features and innovative values alter journalistic cross-channel and cross-sectional working procedures

FINAL PROOF

For H3, cross-beat collaboration is not significantly influenced by innovative values, the working environment, or sociodemographic characteristics considered in this model. Therefore, $\mathrm{H} 3$ is dismissed. 
How structural multi-platform newsroom features and innovative values alter journalistic cross-channel and cross-sectional working procedures FINAL PROOF

Table 3: Differences in innovative values by structural newsroom features

\begin{tabular}{|c|c|c|c|c|c|c|c|c|c|c|c|c|c|c|}
\hline \multirow[b]{3}{*}{$\mathrm{n}$} & & & \multicolumn{4}{|c|}{ Serving } & \multicolumn{4}{|c|}{ Work in } & \multicolumn{4}{|c|}{ Editorial office has central news desk } \\
\hline & \multirow{2}{*}{\multicolumn{2}{|c|}{$\begin{array}{c}\text { Total } \\
47\end{array}$}} & \multirow{2}{*}{\multicolumn{2}{|c|}{$\begin{array}{l}\text { Mono-channel } \\
24\end{array}$}} & \multirow{2}{*}{\multicolumn{2}{|c|}{$\begin{array}{l}\text { Multi-channel } \\
23\end{array}$}} & \multirow{2}{*}{\multicolumn{2}{|c|}{$\begin{array}{c}\text { Single office } \\
13\end{array}$}} & \multirow{2}{*}{\multicolumn{2}{|c|}{$\begin{array}{c}\text { Open-plan office } \\
34\end{array}$}} & \multirow{2}{*}{\multicolumn{2}{|c|}{$\begin{array}{l}\text { No } \\
23\end{array}$}} & \multirow{2}{*}{\multicolumn{2}{|c|}{$\begin{array}{l}\text { Yes } \\
24\end{array}$}} \\
\hline & & & & & & & & & & & & & & \\
\hline & Mean & SD & Mean & $\mathrm{SD}$ & Mean & SD & Mean & $\mathrm{SD}$ & Mean & SD & Mean & SD & Mean & SD \\
\hline $\begin{array}{l}\text { Innovative value index } \\
(1-4)^{1}\end{array}$ & 4.68 & .92 & $4.26_{\mathrm{a}}$ & 1.03 & $5.11_{\mathrm{b}}$ & .52 & $4.38 \mathrm{a}$ & 1.07 & $4.79 \mathrm{a}$ & .84 & $4.36_{\mathrm{a}}$ & 1.02 & $4.98_{b}$ & .70 \\
\hline $\begin{array}{l}\text { Open for new } \\
\text { technologies (1) }\end{array}$ & 4.96 & 1.02 & $4.67 \mathrm{a}$ & 1.27 & $5.26_{b}$ & .54 & $4.54 \mathrm{a}$ & 1.39 & $5.12_{\mathrm{a}}$ & .81 & $4.91_{\mathrm{a}}$ & 1.24 & $5.00_{\mathrm{a}}$ & .78 \\
\hline $\begin{array}{l}\text { Open for new working } \\
\text { procedures (2) }\end{array}$ & 4.94 & .99 & $4.63_{\mathrm{a}}$ & 1.17 & $5.26_{b}$ & .62 & $4.46_{a}$ & 1.13 & $5.12_{b}$ & .88 & $4.61_{\mathrm{a}}$ & 1.12 & $5.25_{b}$ & .74 \\
\hline $\begin{array}{l}\text { New ideas for addressing } \\
\text { the audience ( } 3 \text { ) }\end{array}$ & 4.32 & 1.29 & $3.79 \mathrm{a}$ & 1.44 & $4.87_{b}$ & .81 & $4.00_{\mathrm{a}}$ & 1.29 & $4.44_{a}$ & 1.28 & $3.83_{\mathrm{a}}$ & 1.40 & $4.79_{b}$ & .98 \\
\hline $\begin{array}{l}\text { Identifies new trends in } \\
\text { reporting (4) }\end{array}$ & 4.49 & 1.16 & $3.96_{\mathrm{a}}$ & 1.27 & $5.04_{b}$ & .71 & $4.54 \mathrm{a}$ & .97 & $4.47_{\mathrm{a}}$ & 1.24 & $4.09 \mathrm{a}$ & 1.35 & $4.87_{b}$ & .80 \\
\hline
\end{tabular}

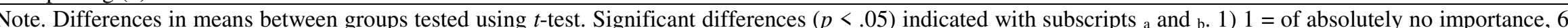

$=$ very important 
How structural multi-platform newsroom features and innovative values alter journalistic cross-channel and cross-sectional working procedures FINAL PROOF

Table 4: Correlations between cross-channel and cross-beat collaboration and innovative values

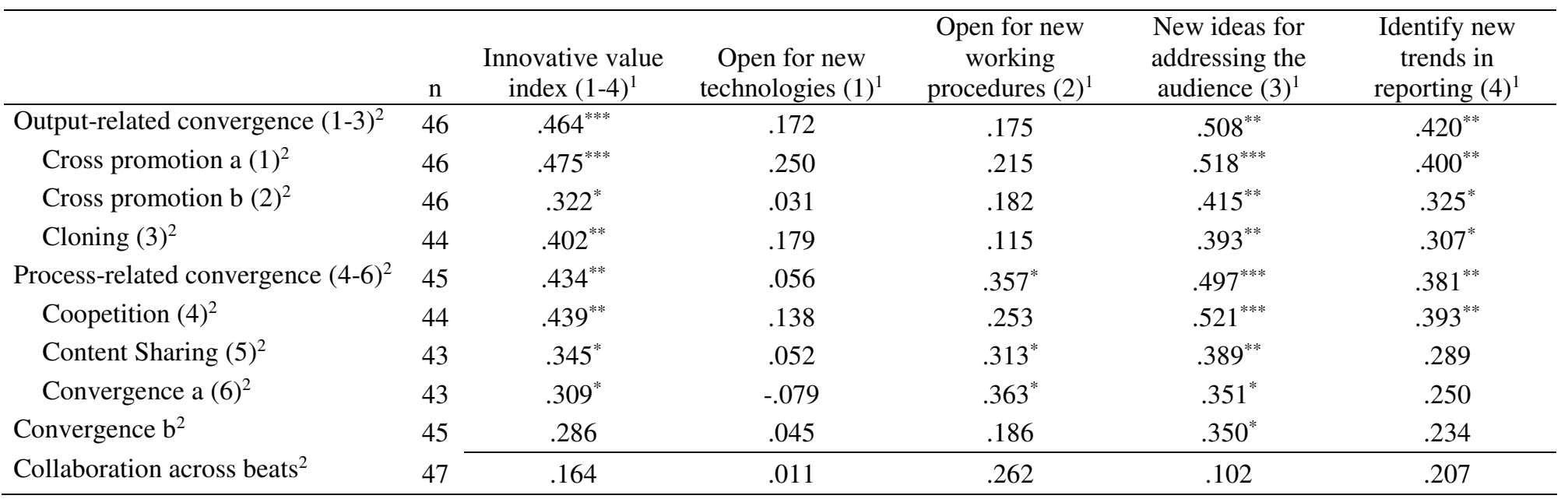

Note. Two-tailed correlations, Spearman's rho. 1) $1=$ of absolutely no importance, $6=$ very important. 2$) 1=$ never, $6=$ always. ${ }^{*}: p<.05^{* *}: p<.01{ }^{* * *}: p<.001$. 
Table 5: Differences in cross-channel and cross-beat collaboration by structural newsroom features

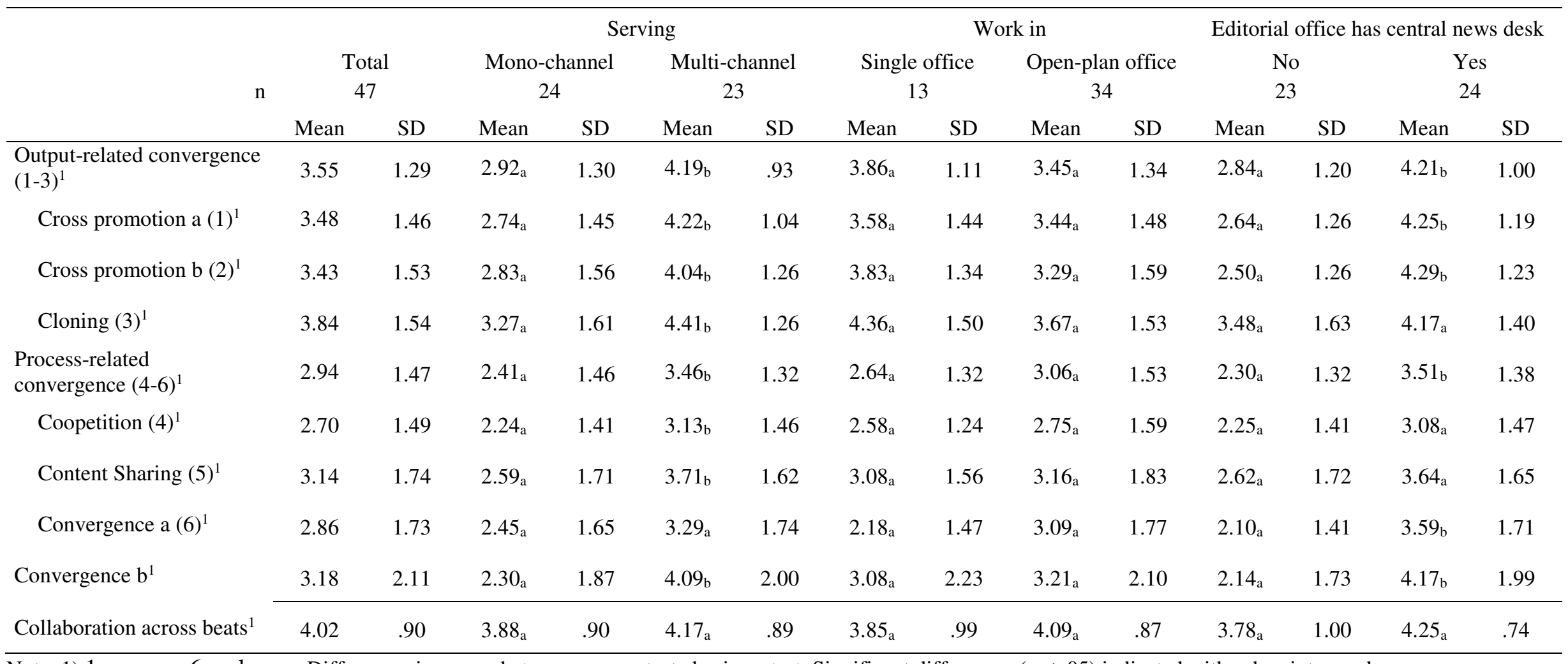

Note. 1) 1 = never, 6 = always. Differences in means between groups tested using $t$-test. Significant differences $(p<.05)$ indicated with subscripts a and ${ }_{\mathrm{b}}$. 
Table 6: Explained variance of innovative values and structural newsroom features in the output- and process-related convergence levels

\begin{tabular}{|c|c|c|c|c|c|c|c|c|c|c|c|c|c|c|c|}
\hline \multirow[t]{2}{*}{ Dependent variable: } & \multicolumn{5}{|c|}{$\begin{array}{l}\text { Output-related convergence }(1-3)^{2} \\
\text { (Cross promotion and cloning) }\end{array}$} & \multicolumn{5}{|c|}{$\begin{array}{c}\text { Process-related convergence }(4-6)^{2} \\
\text { (Coopetition, content sharing, convergence a) }\end{array}$} & \multicolumn{5}{|c|}{ Cross-beat collaboration ${ }^{2}$} \\
\hline & Coef. & SE & Beta & $t$ & $p$ & Coef. & SE & Beta & $t$ & $p$ & Coef. & SE & Beta & $t$ & $p$ \\
\hline \multicolumn{16}{|l|}{ Independent variables } \\
\hline Constant & 1.863 & 1.365 & & 1.366 & .181 & 1.074 & 1.741 & & 617 & .542 & 2.397 & 1.322 & & 1.813 & .079 \\
\hline $\begin{array}{l}\text { New ideas for addressing the } \\
\text { audience }{ }^{1}\end{array}$ & .348 & .168 & .327 & 2.076 & .046 & .277 & .213 & .226 & 1.305 & .201 & -.083 & .163 & -.108 & -.511 & .613 \\
\hline Identify new trends in reporting ${ }^{1}$ & -.051 & .185 & -.041 & -.275 & .785 & .121 & .257 & .079 & .471 & .641 & .093 & .179 & .105 & .520 & .607 \\
\hline $\begin{array}{l}\text { Central news desk } \\
(\text { yes }=1, \text { no }=0)\end{array}$ & .843 & .336 & .335 & 2.512 & .017 & .829 & .421 & .283 & 1.969 & .058 & .440 & .325 & .240 & 1.351 & .186 \\
\hline $\begin{array}{l}\text { Serving mono- }(1) \text { or multi- } \\
\text { channel (2) }\end{array}$ & 648 & .352 & .257 & 1.843 & .074 & .469 & .439 & .160 & 1.067 & .294 & .003 & .342 & .002 & .008 & .994 \\
\hline Gender $(1=$ female, $2=$ male $)$ & -.581 & .415 & -.188 & -1.401 & .170 & -.750 & .518 & -.210 & -1.447 & .158 & -.381 & .402 & -.168 & -.948 & .350 \\
\hline Age (years) & -.023 & .048 & -.159 & -.475 & .638 & -.031 & .059 & -.188 & -.520 & 607 & .054 & .046 & .514 & 1.158 & .255 \\
\hline Professional experience (years) & .013 & .049 & .083 & .259 & .797 & .037 & .061 & .207 & .598 & .554 & -.061 & .047 & -.544 & -1.287 & .207 \\
\hline $\begin{array}{l}\text { Experience in news company } \\
\text { (years) }\end{array}$ & .073 & .045 & .230 & 1.615 & .116 & .044 & .057 & .121 & .776 & .444 & .050 & .044 & .215 & 1.149 & .259 \\
\hline $\begin{array}{l}\text { Management responsibility } \\
(\text { never }=1, \text { always }=6)\end{array}$ & .135 & .096 & .185 & 1.410 & .168 & .278 & .123 & .323 & 2.258 & .031 & .113 & .092 & .214 & 1.229 & .227 \\
\hline $\mathrm{n}$ & 43 & & & & & 42 & & & & & 44 & & & & \\
\hline$F$ & $4.840^{* * *}$ & & & & & $3.638^{* *}$ & & & & & 1.099 & & & & \\
\hline$R^{2}$ & .569 & & & & & .506 & & & & & .225 & & & & \\
\hline Adjusted $R^{2}$ & .451 & & & & & .367 & & & & & .020 & & & & \\
\hline Durbin-Watson & 1.886 & & & & & 1.073 & & & & & 2.059 & & & & \\
\hline
\end{tabular}

Note. 1) 1 = of absolutely no importance, $6=$ very important. 2) $1=$ never, $6=$ always. ${ }^{* *}: p<.01{ }^{* * *}: p<.001$. 
How structural multi-platform newsroom features and innovative values alter journalistic cross-channel and cross-sectional working

\section{DISCUSSION}

This study set out to analyze the influence of structural newsroom features and individual innovative values on journalistic working procedures with an online survey of business journalists in the German-speaking area of Switzerland. The background is the assumption that journalistic values as well as working structures in a news organization change in the face of environmental uncertainty. The focus is the structural change from mono- to multi-platform publishing. For this purpose, this study focuses on innovative values of journalists and structural newsroom features. On the other hand, inertia, especially routine rigidity (Gilbert, 2005), are difficult to overcome for news organizations since they are also social and cultural institutions. Concerning routines, this study looks at output- and process cross-channel working and collaboration cross beats. The online survey of Swiss print and online business journalists reveal the following main results, which are outlined in Figure 3.

1. Individual innovative values of journalists are strongly connected to serving print and online platforms, but are only partly connected to internal structural newsroom features, central news desks, and open-plan offices.

2. Output-related convergence (i.e., using stories for print and online channels) occurs "seldom" to "sometimes," on average. Process-related convergence (i.e., exchange between print and online journalists) occurs "seldom," on average. Frequencies in cross-channel convergent working significantly increases for journalists with high innovative values, who work for print and online channels, and when there is a central news desk. Regression reveals that an increase in outputrelated cross-channel convergence partly depends on innovative values: "New ideas for addressing the audience" and structural newsroom features (i.e., on a central news desk and partly on multi-channel reporting). An increase in process-related cross-channel convergence partly depends on structural newsroom features (i.e., a central news desk) and managerial responsibility. 
How structural multi-platform newsroom features and innovative values alter journalistic cross-channel and cross-sectional working procedures

FINAL PROOF

3. Collaboration across different beats within a news organization occurs "sometimes" on average, which is more often than output- or process-related convergence. Yet, collaboration across beats does not depend on innovative values or structural newsroom features.

Figure 3: Summary of results on organizational responses to environmental uncertainty

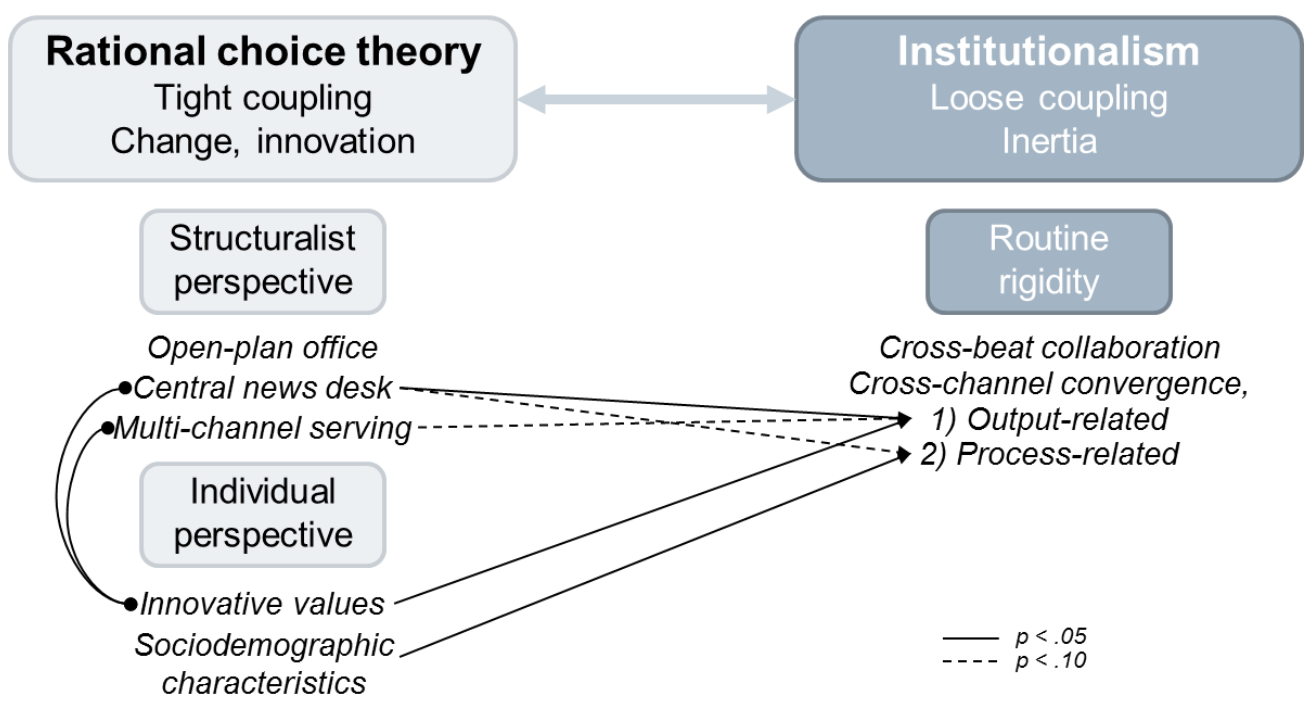

Source: Compiled by the author. Arrows indicate positive relations based on correlations, t-tests, and OLS regressions.

First, this study finds that Swiss news organizations that altered their newsroom structure comprise also journalists whose innovative values increased. This is, structural multi-platform reorganization intervenes with overcoming of "value inertia". This result confirms Slappendel's (1996) argument that changes in structures and individuals within an organization are connected. Structural features and individual values are requirements for innovation (Meier, 2007; Slappendel, 1996; Steensen, 2009). Previous research focusing on the restructuring and convergence process resulted in a change in organizational culture as a consequence (Schein, 1993; Sylvie \& Moon, 2007). The present study combines the individual change in values, which may precede a cultural change within the newsroom, with structural changes and assumes that both aspects intervene. However, whether one causes the other is not determined by present study. In addition, journalists' fluctuations from one 
How structural multi-platform newsroom features and innovative values alter journalistic cross-channel and cross-sectional working procedures FINAL PROOF

news outlet to another as well as the duration of working converged are not considered in this study. Still, these factors as well as the role of change management may serve as additional explanations.

Second, Swiss news organizations do not just employ multi-platform strategies and alter their newsroom structures; print and online reporting procedures become more convergent. Journalists increasingly produce content for print and online channels and collaborate with journalists of other channels. Overcoming routine rigidity (i.e., separate mono-channel reporting) can be ascribed to innovative values, structural newsroom features and processes, as well as management responsibility. Whereas it is not surprising that journalists who work for multiple channels produce content for multiple channels, it may be surprising that this structural feature does not lead to an increase in cross-channel collaboration. An explanation for the latter may be that collaborations across channels are less necessary because of the multiple skills the individual journalist acquires (Wallace, 2013). Or, when business journalists write a text that a producer edits for print and online channels in a next step, this may also explain a less converged collaboration across channels. Such a reusing strategy relates to the cloning level in the convergence continuum (Dailey et al., 2005) that, however, does not differentiate between different roles of a text-producing journalist and a producer who prepares texts for various channels. Therefore, the convergence model may require further adaptation as discussed in Erdal (2011). Instead, stronger predictors for more frequent output-related convergence are higher importance ratings among the innovative value "New ideas for addressing the audience" and the structural feature of a central news desk in the editorial office. Predictors for process-related convergence are the individual characteristic to having managerial responsibility and, as well, the structural feature of a central news desk in the editorial office. These results confirm previous research. Meier (2007) claims that the newsroom structure and Steensen (2009) claims that innovative individuals, among other determinants, are important for innovations in the newsroom.

Third, cross-beat collaboration is more often employed than cross-channel convergence. Therefore, Swiss newsrooms may have already dealt with the challenge to think and act crossdepartmentally, as stated by Meier (2007). However, this result may be due to the cross-sectional 
How structural multi-platform newsroom features and innovative values alter journalistic cross-channel and cross-sectional working procedures

FINAL PROOF

topic of business journalism that is often featured in different sections of a newspaper (e.g., Heinrich \& Moss, 2006). Therefore, business journalists may be more accustomed to working with colleagues of other beats than journalists of other topics. However, the question remains whether business journalists do the preliminary work for colleagues of other beats or vice versa. Also, the question of whether journalists of beats other than business collaborate more often across beats than across channels remains.

Interestingly, routine rigidity is not found to be influenced by gender, age, or journalistic generation, although this is suggested by previous research (Larsson, 2012; Ryfe, 2009). Solely managerial responsibility among the measured demographic variables leads to overcoming routine rigidity for process-related, cross-channel convergence. Hence, it may not be just the quantity of journalistic experience and invested resources in working processes, but change requires the understanding of a bigger picture, which may depend on a higher level of responsibility.

This study did not consider resource rigidity (i.e., investment strategy) or revenue models of news outlets. These aspects may further explain working environment and routines within a news organization. Further research could also relate resource and routine rigidity to journalistic print and online outcome since previous research criticizes the quality of online news for example in Switzerland (Schranz \& Eisenegger, 2012). Studies on these research topics may be located within the theoretical model on organizational responses to environmental uncertainty, as outlined in Figure 1.

\section{CONCLUSIONS AND IMPLICATIONS}

This study confirms that structures, values, and procedures are interconnected subjects to change in news organizations, which supports previous research on newsrooms (Achtenhagen \& Raviola, 2009; Steensen, 2009). The newsroom structure plays an important role for working procedures and, therefore, in the innovations process, as suggested by Meier (2007). However, not all architectural newsroom features are effective. For example, one may expect that open-plan offices stimulate greater collaboration between journalists of different beats or channels. Yet only features 
How structural multi-platform newsroom features and innovative values alter journalistic cross-channel and cross-sectional working procedures

FINAL PROOF

that directly require changes in working procedures, such as being responsible for multi-channel reporting and holding a central news desk, are efficient for overcoming routine rigidity. Also, in terms of reporting performance, Olsson (2009, p. 459) points out that a decentralized newsroom structure is counterproductive when reporting an unforeseen crisis event because journalists "could not draw upon everyday routines in order to handle the event." Therefore, a central news desk may be a multipurpose effective newsroom feature.

Deuze (2008b) argues that journalism insufficiently takes the demands of the audience into account. Although audience orientation became more important and the audience is scrutinized, output changes are rarely made (Deuze, Neuberger, \& Paulussen, 2004; Himelboim \& McCreery, 2012; Lowrey \& Woo, 2010). The present results reveal that when journalists rate it important to find new ways to address the audience, news elements (e.g., cross promotion) and channels used changes as well. This may indicate that journalistic output changes according to audience demands. However, since ideas mentioned in an open-end question for new ways of audience addressing are notions that are already well-established, one could also argue that output changes occur only within already known parameters. Therefore, content changes may mimic each other, which would lead to a moreof-the-same, rather than real, innovation. However, this study cannot make statements about news content but must leave this topic to further research.

When taking up Lowrey and Woo's (2010) question, whether news organizations behave like adapting businesses or inertial institutions, the present results demonstrate that the former applies when structural and individual requirements are given. Although Domingo (2008) argues that newsrooms are prevented from innovation through inertia, this study comes to the conclusion that a multi-platform strategy leading to the implementation of a central news desk is connected to innovative values of journalists, which in turn changes working procedures. A multi-platform strategy, as well as other structural newsroom features, is effective in overcoming procedural inertia, which is essential for the news organization and its innovative capacities (Corstjens et al., 2011; Huang, Lai, Lin, \& Chen, 2013). However, overcoming routine rigidity may not be sufficient for "real" innovation 
How structural multi-platform newsroom features and innovative values alter journalistic cross-channel and cross-sectional working procedures

FINAL PROOF

and avoiding isomorphism. Hence, a remaining challenge is not to raise innovative awareness across journalists but to identify and implement new ways to reach and attract audiences.

Media managers should be aware that different kinds of inertia have to be overcome when innovative capacities are to be developed. Environmental change has to be detected and suitable reactions deployed by managerial and journalistic actors within the news organization. Investment, structures, values, and/or processes may need to be changed. For media business implications, managers may want to evaluate whether their structural newsroom features require an overcoming of formerly decentralized working routines. If so, they may want to evaluate how intensely journalists of print and online channels - if the news outlet distinguishes between print and online journalists - as well as different beats and departments collaborate. To alter structural newsroom features may be an easier task than to change individual values, newsroom cultures, and working processes. However, many surveyed journalists deploy converged working processes and are aware of the importance of innovative reporting. The hardest part may be to actually identify and implement innovative ways of reporting. Yet since journalists expressed first ideas within a short online questionnaire in the present study, media managers should further use the innovative capacity of journalists in a bottom-up process to find and test new ways of addressing the audience.

\section{References}

Achtenhagen, L., \& Raviola, E. (2009). Balancing tensions during convergence: Duality management in a newspaper company. International Journal on Media Management, 11(1), 32-41. doi:10.1080/14241270802518505

Blackmore, K. L., \& Nesbitt, K. V. (2009). Defending against turbulent conditions: Results from an agent-based simulation. International Journal of Business Studies, 17(1), 127-148.

Bundesamt für Statistik. (2012). Internet in den Schweizer Haushalten: Ergebnisse der Erhebung Omnibus IKT 2010. Retrieved from http://www.bfs.admin.ch/bfs/portal/de/index/themen/16/22/publ.Document.155228.pdf

Burke, W. W., Lake, D. G., \& Paine, J. W. (2009). Organization change: A comprehensive reader. The JosseyBass business and management series. San Francisco: Jossey-Bass.

Christensen, C. M. (1997). The innovator's dilemma: When new technologies cause great firms to fail. The management of innovation and change series. Boston, MA: Harvard Business School. 
How structural multi-platform newsroom features and innovative values alter journalistic cross-channel and cross-sectional working procedures

FINAL PROOF

Corstjens, M., Umblijs, A., \& Wang, C. (2011). The power of inertia: Conservatism in marketing resource allocation, 51(2), 356-372. doi:10.2501/JAR-51-2-356-372

Dailey, L., Demo, L., \& Spillman, M. (2005). The convergence continuum: A model for studying collaboration between media newsrooms. Atlantic Journal of Communication, 13(3), 150-168. doi:10.1207/s15456889ajc1303_2

Deuze, M. (2004a). What is multimedia journalism? Journalism Studies, 5(2), 139-152. doi:10.1080/1461670042000211131

Deuze, M. (2008b). The changing context of news work: Liquid journalism and monitorial citizenship. International Journal of Communication, (2), 848-865. Retrieved from http://ijoc.org/index.php/ijoc/article/view/290/197

Deuze, M. (2008). Professional identity in a participatory media culture. In T. Quandt \& W. Schweiger (Eds.), Journalismus online - Partizipation oder Profession? (pp. 251-261). Wiesbaden: VS Verlag.

Deuze, M., Neuberger, C., \& Paulussen, S. (2004). Journalism education and online journalists in Belgium, Germany, and the Netherlands. Journalism Studies, 5(1), 19-29. doi:10.1080/1461670032000174710

Domingo, D. (2008). Interactivity in the daily routines of online newsrooms: dealing with an uncomfortable myth, 13(3), 680-704. doi:10.1111/j.1083-6101.2008.00415.x

Eisenegger, M., Orizet, J., \& Schranz, M. (2013). Medien im Social Web - Journalistischer Mehrwert? Luzern: Schwabe Verlag Basel.

Erdal, I. J. (2011). Coming to terms with convergence journalism: Cross-media as a theoretical and analytical concept. Convergence: The International Journal of Research into New Media Technologies, 17(2), 213-223. doi:10.1177/1354856510397109

Esser, F. (1998). Editorial structures and work principles in British and German newsrooms. European Journal of Communication, 13(3), 375-405. doi:10.1177/0267323198013003004

García Avilés, J. A., Meier, K., Kaltenbrunner, A., Carvajal, M., \& Kraus, D. (2009). Newsroom integration in Austria, Spain and Germany. Journalism Practice, 3(3), 285-303. doi:10.1080/17512780902798638

Gilbert, C. G. (2005). Unbundling the structure of inertia: Resource versus routine rigidity. Academy of Management Journal, 48(5), 741-763. doi:10.5465/AMJ.2005.18803920

Gilbert, C. G. (2006). Change in the presence of residual fit: Can competing frames coexist? Organization Science, 17(1), 150-167. doi:10.1287/orsc.1050.0160

Hagen, L. M. (2008). Public Opinion and the Economy. In W. Donsbach \& M. W. Traugott (Eds.), The SAGE handbook of public opinion research (pp. 527-533). London: Sage.

Hannan, M. T., \& Freeman, J. (1984). Structural inertia and organizational change. American Sociological Review, 49(2), 149-164. doi:10.2307/2095567

Heinrich, J., \& Moss, C. (2006). Wirtschaftsjournalistik: Grundlagen und Praxis. Wiesbaden: VS Verlag.

Himelboim, I., \& McCreery, S. (2012). New technology, old practices: Examining news websites from a professional perspective. Convergence: The International Journal of Research into New Media Technologies, 18(4), 427-444. doi:10.1177/1354856511429648

Huang, H.-C., Lai, M.-C., Lin, L.-H., \& Chen, C.-T. (2013). Overcoming organizational inertia to strengthen business model innovation: An open innovation perspective. Journal of Organizational Change Management, 26(6), 977-1002. doi:10.1108/JOCM-04-2012-0047 
How structural multi-platform newsroom features and innovative values alter journalistic cross-channel and cross-sectional working procedures

FINAL PROOF

Keel, G., Wyss, V., Stoffel, A., \& Saner, M. (2010). Auswirkungen des Internets auf die journalistische Praxis und berufskulturelle Normen. Schlussbericht. Retrieved from http://www.bakom.admin.ch/themen/radio_tv/01153/01156/03479/index.html?lang=de

Kolodzy, J. (2006). Convergence journalism: Writing and reporting across the news media. Lanham, Md: Rowman \& Littlefield.

Larsson, A. O. (2012). Interactivity on Swedish newspaper websites: What kind, how much and why? Convergence: The International Journal of Research into New Media Technologies, 18(2), 195-213. doi:10.1177/1354856511430184

Lischka, J. A., \& Siegert, G. (2013). Beeinflussen Wirtschaftsnachrichten auch Wirtschaftserwartungen von Experten? Die Prognosequalität von öffentlich-rechtlichen und Service public Wirtschaftsnachrichten für Erwartungen von Wirtschaftsexperten in Deutschland und in der Schweiz. Studies in Communication Sciences, 13(2), 174-184. doi:10.1016/j.scoms.2013.09.002

Lowrey, W. (2005). Commitment to newspaper-TV partnering: A test of the impact of institutional isomorphism. Journalism \& Mass Communication Quarterly, 82(3), 495-515. doi: $10.1177 / 107769900508200302$

Lowrey, W. (2011). Institutionalism, news organizations and innovation. Journalism Studies, 12(1), 6479. doi:10.1080/1461670X.2010.511954

Lowrey, W., \& Woo, C. W. (2010). The news organization in uncertain times: Business or institution? Journalism \& Mass Communication Quarterly, 87(1), 41-61. doi:10.1177/107769901008700103

Massey, B. L., \& Ewart, J. (2012). Sustainability of organizational change in the newsroom: A case study of Australian newspapers. International Journal on Media Management, 14(3), 207-225. doi:10.1080/14241277.2012.657283

Meier, K. (2007). Innovations in Central European newsrooms. Journalism Practice, 1(1), 4-19. doi:10.1080/17512780601078803

Meier, W. A. \& Leonarz, M. (2011). Zur Lage der Presse in der Schweiz. Wissenschaftliches Papier für den Verein Medienkritik Schweiz. Retrieved from www.swissgis.uzh.ch/medien/LagederPresse.pdf

Miller, D. (1994). What happens after success: The perils of excellence. Journal of Management Studies, 31(3), 325-358. doi:10.1111/j.1467-6486.1994.tb00621.x

Miller, D., \& Friesen, P. H. (1983). Strategy-making and environment: The third link. Strategic Management Journal, 4(3), 221-235. doi:10.1002/smj.4250040304

Mitchelstein, E., \& Boczkowski, P. J. (2009). Between tradition and change: A review of recent research on online news production. Journalism, 10(5), 562-586. doi:10.1177/1464884909106533

Olsson, E.-K. (2009). Media crisis management in traditional and digital newsrooms. Convergence: The International Journal of Research into New Media Technologies, 15(4), 446-461. doi:10.1177/1354856509342780

Pfeffer, J., \& Salancik, G. R. (2003). The external control of organizations. A resource dependence perspective. Stanford, CA: Stanford Business Books.

Phillips, A., Singer, J. B., Vlad, T., \& Becker, L. B. (2009). Implications of technological change for journalists' tasks and skills. Journal of Media Business Studies, 6(1), 61-85.

Powell, W. W., \& DiMaggio, P. (Eds.). (1991). The new institutionalism in organizational analysis. Chicago: University of Chicago Press.

Ryfe, D. M. (2009). Structure, agency, and change in an American newsroom. Journalism, 10(5), 665683. doi:10.1177/1464884909106538 
How structural multi-platform newsroom features and innovative values alter journalistic cross-channel and cross-sectional working procedures

FINAL PROOF

Schein, E. H. (1993). On dialogue, culture, and organizational learning. Organizational Dynamics, 22(2), 40-51. doi:10.1016/0090-2616(93)90052-3

Schranz, M., \& Eisenegger, M. (2012). Onlinenews - Die Qualität von Presse- und Onlinetiteln im Direktvergleich. In fög-Forschungsbereich Öffentlichkeit und Gesellschaft (Ed.), Qualität der Medien. Jahrbuch 2012 (pp. 316-331). Basel: Schwabe.

Singer, J. B. (2004). Strange bedfellows? The diffusion of convergence in four news organizations. Journalism Studies, 5(1), 3-18. doi:10.1080/1461670032000174701

Singer, J. B. (2005). The political j-blogger. 'Normalizing' a new media form to fit old norms and practices. Journalism, 6(2), 173-198. doi:10.1177/1464884905051009

Slappendel, C. (1996). Perspectives on Innovation in Organizations. Organization Studies, 17(1), 107129. doi:10.1177/017084069601700105

Steensen, S. (2009). What's stopping them?: Towards a grounded theory of innovation in online journalism. Journalism Studies, 10(6), 821-836. doi:10.1080/14616700902975087

Sylvie, G., \& Moon, S. J. (2007). Framing change: Who's in charge in the newsroom. In L. Achtenhagen (Ed.), Organizing media. Mastering the challenges of organizational change (pp. 89-124). Jönköping: Jönköping International Business School.

Wallace, S. (2013). The complexities of convergence: Multiskilled journalists working in BBC regional multimedia newsrooms. International Communication Gazette, 75(1), 99-117.

doi:10.1177/1748048512461764

Wilczek, B. (2014). Redaktionelle Konvergenz und Trade-offs bei der Sicherung journalistischer Qualität. In H. Rau (Ed.), Medienökonomie: Vol. 7. Digitale Dämmerung. Die Entmaterialisierung der Medienwirtschaft (pp. in preparation). Baden-Baden: Nomos.

Wilke, J. (2003). The history and culture of the newsroom in Germany. Journalism Studies, 4(4), 465477. doi:10.1080/1461670032000136569

Zucker, L. G. (1987). Institutional Theories of Organization. Annual Review of Sociology, 13, 443-464.

Zwicky, P. (2012). Journalistische Produktion unter neoliberalen Bedingungen: Eine konflikttheoretische Analyse von Tageszeitungen aus Deutschland, Österreich und der Schweiz. Baden-Baden: Nomos. 